\title{
Milk formulas: Present day information and recommendations
}

\author{
Laura Florescu', Oana-Raluca Temneanu', Dana-Teodora Anton Paduraru², \\ Dana Elena Mindru' \\ ${ }^{1}$ Discipline Infant Care, Department of Mother and Child Medicine, "Gr. T. Popa" University of \\ Medicine and Pharmacy, lasi, Romania \\ 2Discipline Pediatrics, Department of Mother and Child Medicine, "Gr. T. Popa" University of \\ Medicine and Pharmacy, lasi, Romania
}

\begin{abstract}
A healthy child passes through a process of growth and harmonious development, his environment and food quality representing determining premises of his health, especially during the first two years. When breastfeeding is impossible due to the absence of milk secretion installation or to an insufficient amount of maternal milk, the alternative sources of feeding consist either in the administration of milk formulas or, under precarious social-economic conditions, in cow milk. As each infant has its individual needs, there is a variety of milk formulas, such that to provide the infant an adequate quantitative and qualitative nutrition, optimum for a harmonious development. There are several categories of formulas, based on proteins from milk or soy, hy-drolyzed proteins and amino acids, as well as differences between the products from each category.
\end{abstract}

Keywords: milk formulas, infant formula, follow-on formula

Nowadays, world authorized organisms (WHO - World Health Organization, UNICEF - United Nations International Children Emergency Fund), as well as national organs (IMCP - Institute for Maternity and Child Protection) uphold the natural feeding and state that this represents a public health problem. The recommendation agrees with the dynamic of scientific discoveries from the last decades that sustain the importance of maternal milk administration for child and future adult development. The most important world religions also proclaim mother's obligation to breastfeeding, for instance the Christianity, through the voice of Pope Jean Paul the $2^{\text {nd }}$, the Judaism through the Old Testament and Islam through Koran.

At the world level, one can quote among the pro-breastfeeding initiatives, the International Breastfeeding Week (1) or the existence of breastfeeding counselors in different cities. International statistical data represent a warning signal, as the rate of adhesion to breastfeeding keeps decreasing (2). That is why the world and national decisional forums adopted a legislative framework favorable to natural feeding.

Optimum infants' feeding implies both a quantitative and a qualitative dimension. The registered upward or downward unbalances can result in malnutrition or over nutrition, as well as food deficiency due to a persistent deficit of a certain nutrient. One should take into account certain infant nourishing peculiarities, which imply, first of all, the very high caloric needs of infant (measured in $\mathrm{kg}$ body/day). During the first months of life, these needs will register a progressive decrease until the puberty period, when they tend to increase considerably again. A major importance is granted to the protein fraction that must be both constant, to provide the physiologic growth rhythm, and qualitatively adequate, the infants needing more essential and semi-essential amino acids, as they have in- 
creased water necessities, which are susceptible to quick fluctuations in the case of some increased losses.

Nowadays, unanimously accepted recommendations are for exclusive breast-feeding up to six months, initiation of complementary feeding after this age, breastfeeding continuing up to the age of 2 years (3).

When the infant can not beneficiate of breast milk (partly or entirely), one should resort to the administration of preparations based on powder milk obtained by processing cow or goat milk or soy, with a composition as similar as possible to the breast milk. The milk formulas industry has developed in time such that, regardless the associated pathology or individual peculiarities, one will certainly find an adequate formula that provides suitable growth and development.

"Infant formulas" are food preparations meant to be used by infants during the first months of life, satisfying by themselves the demands of infants' nutrition and harmonious development until the introduction of an adequate complementary nutrition.

"Follow-on formulas" represent a nutrient destined to infants when an adequate complementary feeding is introduced and constitutes the main liquid element of the infant's progressively diversified feeding.

The infant formula and the follow-on formula are complex products elaborated especially for a vulnerable consumers group. In order to be able to use them safely, one needs to establish detailed demands in terms of their composition and energetic value respectively, as well as the content of macro and micronutrients. These demands must be based on the most recent scientific notifications of the European Food Safety Authority (EFSA) stipulated in its notification related to the essential composition of the infant formulas and follow-on formulas (4).

Classification of milk formulas is made in terms of age groups for which they are recommended, or depending on composition $(5,6)$.

Formulas classification in terms of age:

- low birth weight infant formulas - LWBF;

- infants formulas (0- 6/12 months) - IF;

- follow-on formulas (6-12/36 months) (FOF);

- growing- up milk (over 10/12 months) GUM;

- special formulas for infants with certain physiologic and/or metabolic needs (FSMP) (formulas for special medical purpose).
Formulas classification in terms of composition:

- with cow milk proteins;

- with whey proteins;

- with soy proteins;

- with amino acid as sole protein source (elemental formulas);

- with thickening agents (anti-regurgitationAR);

- lactose free (7).

The new European Union legislation related to milk formulas was published in the Official Journal of EU in February 2016:

- DELEGATE REGULATION (EU) 2016/127 of the COMISSION of 25 September 2015, addendum to the (EU) Regulation no. 609/2013 of the European Parliament and the Council, related to specific requirements for composition, and the information for infant formulas and follow-on formulas, and concerning the information on infant and small age children feeding.

- DELEGATE REGULATION (EU) 2016/128 of the COMISSION of 25 September 2015, addendum to the (EU) Regulation no. 609/2013 of the European Parliament and the Council, concerning specific requirements in terms of composition, and the information applicable to nutrients destined for some special medical purposes (8).

These documents clearly specify the energetic needs (Table 1), and the quantity of micro and macronutrients necessary and admitted for early formulas and follow-on formulas.

TABLE 1. Energetic needs

\begin{tabular}{|c|c|}
\hline Minimum & Maximum \\
\hline $250 \mathrm{~kJ} / 100 \mathrm{ml}$ & $293 \mathrm{~kJ} / 100 \mathrm{ml}$ \\
\hline$(60 \mathrm{kcal} / 100 \mathrm{ml})$ & $(70 \mathrm{kcal} / 100 \mathrm{ml})$ \\
\hline
\end{tabular}

\section{Proteins}

Among the known essential micro and macronutrients, the proteins are the most important for organism development and health. Proteins are organic macromolecular substances formed of simple or complex of amino acids chains. They are present inside the cells of all living organisms in proportion of over $50 \%$ of the dry weight. All the proteins contain the same 20 amino acids, but in different combinations (inclusively with other components - glucoses, lipids, organic elements, etc) and different chemical arrangements. Proteins influence all the aspects of growth and development. Breast milk contains the ideal quantity and quality of proteins. The breast milk protein composition evolves in time, to meet the evolving infant needs (9). 
Unlike the breast milk, some standard milk formulas for infants overload with proteins the infants from a critical age. The scientific evidences reveal the importance of protein contribution for the longterm metabolic health. According to "Early Protein Hypothesis", the excessive protein contribution during the first year of life "programs" the trend to a rapid weight growth and generation of adipose cells (adipogenesis activity) (10).

Utilization of hydrolyzed protein products as a protein source in the infant formulas and follow-on formulas was permitted for many years on the ground of the Directive 2006/141/EC. According to the new EU legislation, the protein quantity in the infant formulas based on cow's milk proteins was modified from 1.8-3 g/100 kcal to 1.8-2.5 g/100 $\mathrm{kcal}$, and in the infant formulas based on protein hydrolyzed products the present demands are of $1.8-2.8 \mathrm{~g} / 100 \mathrm{kcal}$, while the old limits were $<2.8 \mathrm{~g} / 100 \mathrm{kcal}$. Formulas based oh hydrolyzed protein products contain as protein source the demineralized sweet whey proteins, derived from cow milk after enzymatic casein precipitation by means of rennin, consisting of:

a) $63 \%$ whey protein segregate without caseinglycomacropeptides, with a minimum protein content of $95 \%$ of dry substance, a protein adulteration smaller than $70 \%$ and a maximum ash content of $3 \%$, as well as

b) $37 \%$ sweet whey protein concentrate with a minimum protein content of $87 \%$ of dry substance, a protein adulteration smaller than $70 \%$ and a maximum ash content of $3.5 \%$.

\section{Lipides}

Mandatory addition of docosahexaenoic acid (DHA) to the infant formulas and follow-on formulas is a new demand introduced by the present regulation, recently recommended by the Authority in its notification regarding the essential composition of the infant formulas and follow-on formulas (DHA: $20-50 \mathrm{mg} / 100 \mathrm{kcal}$ ). The limits for the linoleic and alpha- linoleic acids were also modified, and the limits for the myristic and lauric acids were eliminated. One forbids the utilization of the following substances: benne oil and cotton seed oil.

\section{Carbohydrates}

One can use only the following carbohydrates: lactose, maltose, saccharose, glucose, glucose syrup or dehydrated glucose syrup, maltodextrins, heat pretreated starch (which naturally does not contain gluten), gelatinized starch (which naturally does not contain gluten).

One can add only in formulas based on hydrolyzed protein products:

- Saccharose max $20 \%$ from carbohydrates

- Glucose <2g/100 kcal

- Glucose syrup or dehydrated glucose syrup < $0.84 \mathrm{~g} / 100 \mathrm{kcal}$.

\section{Lactose}

Specification "only lactose" can be used for infant formulas and follow-on formulas under the condition that lactose is the sole sacharid in the product.

Specification "no lactose" can be used in infant formulas and follow-on formulas when lactose content in the product does not exceed $2.5 \mathrm{mg} / 100$ $\mathrm{kJ}(10 \mathrm{mg} / 100 \mathrm{kcal})$.

One can add fructo-oligosaccharides and galacto-oligosaccharides in the infant formulas. In this case, their content exceeds $0.8 \mathrm{mg} / 100 \mathrm{ml}$, in a combination of $90 \%$ oligogalactosyl - lactose and $10 \%$ oligofructosyl- saccharose with higher molecular weight. One can use other combinations and maximum contents of fructo-oligosaccharides and galacto-oligosaccharide, under the condition to demonstrate that they are adequate for infants.

More severe restrictions are established for a small number of pesticide or pesticide-metabolites, for which even a maximum residue limit (MRL) of $0.01 \mathrm{mg} / \mathrm{kg}$ could lead in the most severe case of consumption in excess, to an exposure that exceeds the daily acceptable dose (DAD) for infants and small age children (11).

A special category is represented by infants with food allergy, with or without family atopy history. The nutrition from the first month of life can influence the probability to develop an allergy later. As the result of the exposure to nutrient antigens, an immunologic processing occurs at the level of mucous intestinal barrier, which can develop both protection and food tolerance phenomena, and allergytype phenomena. At present, when exclusive breastfeeding is not possible, one recommend to use a hypoallergenic formula (HA), with scientifically proved effects at infants with allergic family history. The recommendations of the French experts lay the stress on the fact that an H.A. formula should be also used for children with unknown family history.

Among all the infants' food allergies, the allergy to cow's milk proteins (ACMP) is the mostly met and it affects about $3 \%$ of infants (12). ACMP is 
defined as a reproducible adverse reaction to one or more milk proteins (usually to caseins or whey, such as $\beta$-lacto globulin) and it can be $\lg \mathrm{E}$ or non $\lg$ E mediated. ACMP can appear also at exclusively breastfed infants; the phenomenon can occur through protein transfer from mother through breast milk.

It is known that breast milk allergy can imply also allergy to the milk from another mammal, i.e. "cross-reactive allergy" (13).

There are also formulas based on goat milk. Proteins from goat milk are digested better that those from cow milk. According to literature, this is easier digestible, the allergenic load being significantly smaller as compared to cow milk. Yet, one should not forget that the persons who are very sensitive to cow milk proteins need the advice of a doctor before drinking goat milk (14).

The soy-based formulas are available for almost 100 years. Starting from the first utilization of soy formula as a milk substitute for an infant that cannot tolerate a formula based on cow's milk proteins, the composition was continuous improved. Soy protein formulas are recommended in the allergy/ intolerance to cow's milk proteins, yet specifying that there are situations of cross-allergy, in which case one shall use hypoallergenic formulas that contain protein/amino acid hydrolyzed products $(15,16)$.

Low birth weight (LBW) newborns have special characteristics and needs, no matter whether they belong or not to preterm category (17). Formulas recommended to LBW infants have a higher protein content- mainly from whey, higher quantities of sugar and lipids (vegetal oils and triglycerides with medium chain), as well as a bigger protein/ calories ratio as compared to standard formulas (18). Human milk fortifiers synthesized from cow

\section{REFERENCES}

1. http://www.who.int/mediacentre/events/2016/world-breastfeedingweek/en/.

2. Lawrence R.A., Lawrence R.M. The Revolution in Infant Feeding. In: Breastfeeding, a guide for the medical profession, $8^{\text {th }}$ edition, Elsevier. 2015; 1-33.

3. http://www.who.int/topics/breastfeeding/en/.

4. Scientific Opinion on the essential composition of infant and follow-on formulae EFSA Journal. 2014;12(7):3760

5. Agostoni C., Domelof M. Infant Formulae: From ESPGHAN Recommendations Towards ESPGHAN - coordinated global Standards. J. of Gastroenterology and Nutrition. 2005; 41:580-583.

6. Fomon S.J. Assessement of Growth of Formula - Fed Infants Evolutionary Considerations. Pediatrics. 2004; 113(2):389-393. milk are mainly used to feed the newborn babies with birth weight under $1,500 \mathrm{~g}$, the dilution liquid during hospitalization being mother breast milk. In the case of preterm newborn infants, especially those with VLBW, mother breast milk has an insufficient protein and calories content. The utilization of the fortified human milk determines an adequate stature-weight recovery among preterm babies, satisfying the nourishing needs specific for this infant category (19).

\section{CONCLUSIONS}

The first 1,000 days from the very beginning of pregnancy are essential for healthy development of the future adult. Breast milk represents the ideal nutrient for infants. WHO recommends exclusive breastfeeding up to six months, continued with breastfeeding as long as possible, accompanied by nourishment diversification. In situations when the infant cannot beneficiate of breastfeeding - partially or entirely- one should resort to the administration of adequate powder-milk preparations. Understanding the necessity of the administration of a qualitatively and quantitatively adequate nourishment led to the development of milk formulas that provide the necessary macro and micronutrients for both, healthy infants and those who manifest various pathologies (for example, gastro-esophageal reflux, intolerance to lactose, allergy to cow's milk protein, malabsorption syndrome, preterm infants). Dietetic formulas are "safe" from the standpoint of nutrient contribution, i.e. they are complete from nutritional standpoint and induce no deficiency. The administration of a milk formula will be performed after nourishing advice of a doctor, who will identify the peculiarities of the growth and development for each infant apart.

Conflict of interest: none declared Financial support: none declared

7. Florescu L., Balanica G. Puericultură-elemente practice de puericultură pentru copilul 0-3 ani. Iaşi: Editura „Gr. T. Popa“ U.M.F. Iaşi, 2012.

8. https://lege5.ro/JurnalOficial/jurge4dknzqge/jurnalul-oficial-al-uniuniieuropene-nr-25-02-02-2016

9. Ballard O., Morrow A.L. Human Milk Composition: Nutrients and Bioactive Factors. Pediatr Clin North Am. 2013; 60(1):49-74.

10. Koletzko B. et al. Can infant feeding choices modulate later obesity risk? Am J Clin Nutr. 2009; 89(Suppl): 1502S-1508S.

11. http://eur-lex.europa.eu/legal-content/EN/TXT/?qid=1487099331486\& uri=CELEX:32016R0127

12. Koletzko S. et al. Diagnostic Approach and Management of Cow's-Milk Protein Allergy in Infants and Children: ESPGHAN GI Committee Practical Guidelines. JPGN 2012; 55:221-229. 
13. Sicherer S.H. Clinical implications of cross-reactive food allergens. J Allergy Clin Immunol. 2001;108(6):881-890.

14. http://www.dgc.co.nz/goat_milk_formula.cfm

15. Joeckel R.J., Phillips S.K. Overview of infant and pediatric formulas. Nutr Clin Pract. 2009; 24(3):356-362.

16. Bhatia J., Greer F. Use of soy protein-based formulas in infant feeding. American Academy of Pediatrics Committee on Nutrition. Pediatrics. 2008;121(5):1062-1068.

17. Quigley M., McGuire W. Formula versus donor breast milk for feeding preterm or low birth weight infants. Cochrane Database Syst Rev. 2014; (4):29-71.
18. Bi C.Y., Ru X.F., Feng Q. et al. The status of protein intake and energy supply in the early life of very/extremely low birth weight infants. Zhonghua Er Ke Za Zhi. 2013; 51(5):349-355.

19. Agostoni et al. Enteral Nutrient Supply for Preterm Infants: Commentary From the European Society of Paediatric Gastroenterology, Hepatology and Nutrition Committee onNutrition, Journal of Pediatric Gastroenterology and Nutrition. 2010; Vol. 50, No. 1. 